\title{
PEMERIKSAAN JUMLAH KOLONI MIKROORGANISME DI UDARA PADA PEMUKIMAN WARGA DI SEKITAR TEMPAT PEMBUANGAN AKHIR SAMPAH TERJUN
}

\author{
Nin Suharti, Halimah Fitriani P. \\ Jurusan Kebidanan Poltekkes Kemenkes Medan
}

\begin{abstract}
Abstrak
Keterbatasan tempat tinggal di daerah perkotaan semakin bertambah dari waktu ke waktu, karena pertumbuhan penduduk lebih cepat dibandingkan dengan ketersediaan lahan. Kondisi ini mengakibatkan munculnya permasalahan perumahan yang semakin sulit di perkotaan.Untuk mengatasi kebutuhan perumahan mereka cenderung tinggal di daerah pinggiran, termasuk masyarakat umum dan pemulung yang bermukim di sekitar lokasi tempat pembuangan akhir sampah (TPAS). Secara khusus penelitian ini bertujuan untuk mengetahuiJumlah koloni mikroorganisme di udara pada pemukiman warga sekitar TPAS Terjun. Kegiatan dilakukan di TPAS dan sekitarnya. Jumlah mikroorganisme yang direkomendasikan oleh Menteri Kesehatan RI No:1077/MENKES/PER/V/2011 mengenai udara yang sehat adalah jumlah mikroorganisme $<700 \mathrm{CFU} / \mathrm{m}^{3}$ udara. Penelitian ini dilaksanakan pada bulan Juli s/d Agustus 2018 bertujuan untuk mengetahui jumlah mikroorganisme udara pada lokasi tempat pembuangan akhir sampah (TPAS) Terjun Medan dan tempat tinggal masyarakat di sekitarnya. Metode yang digunakan pada penelitian ini adalah Experimen menggunakan Culture pada media Plate Cout Agar (PCA) dan alat Air Exampler Mas 100. Hasil penelitian menunjukkan bahwa pada titik pusat TPAS (0 meter) jumlah mikroorganisme udara sebanyak 2874 $\mathrm{cfu} / \mathrm{m}^{3}, 100 \mathrm{~m}$ dari titik pusat TPAS Jumlah Mikroorganisme $2294 \mathrm{cfu} / \mathrm{m}^{3}, 250 \mathrm{~m}$ dari titik pusat TPAS Jumlah Mikroorganisme $1913 \mathrm{cfu} / \mathrm{m}^{3}, 500 \mathrm{~m}$ dari titik pusat TPAS Jumlah Mikroorganisme $966 \mathrm{cfu} / \mathrm{m}^{3}, 750 \mathrm{~m}$ dari titik pusat TPAS Jumlah Mikroorganisme $662 \mathrm{cfu} / \mathrm{m}^{3}, 1000 \mathrm{~m}$ dari titik pusat TPAS Jumlah Mikroorganisme $517 \mathrm{cfu} / \mathrm{m}^{3}$ Semakin jauh dari titik pusat jumlah mikroorganisme udara semakin menurun dengan angka korelasi $95,7 \%$ dan jarak yang aman bagi masyarakat adalah $\geq 750$ meter, karena populasi mikroorganisme udara sudah dibawah standar baku mutu yang ditetapkan $\left(<700 \mathrm{cfu} / \mathrm{m}^{3}\right)$.
\end{abstract}

Kata kunci : TPAS, Jumlah Koloni di Udara, Jarak Pemukiman Warga

\section{PENDAHULUAN}

Keterbatasan tempat tinggal di daerah perkotaan semakin bertambah dari waktu ke waktu, karena pertumbuhan penduduk lebih cepat dibandingkan dengan ketersediaan lahan. Kondisi ini mengakibatkan munculnya permasalahan perumahan yang semakin rumit di perkotaan terutama masalah sanitasi lingkungan yang kurang baik. Penduduk dengan status sosial ekonomi yang rendah bertambah banyak jumlahnya. Untuk mengatasi kebutuhan perumahan mereka cenderung tinggal di daerah pinggiran, termasuk masyarakat umum dan pemulung yang bermukim di sekitar lokasi tempat pembuangan akhir sampah (TPAS). Pemulung yang menjadikan TPAS sebagai sumber mata pencahariannya bahkan mendirikan rumahnya di atas timbunan sampah di lokasi TPAS. Kebutuhan ekonomi yang semakin tinggi dengan kesulitan mencari pekerjaan yang layak membuat para pemulung tetap bertahan tinggal di lokasi TPAS (Soedojo, 2011).

Di sekitar lokasi TPAS Terjun banyak berdiri rumah penduduk dan pemulung. Hal ini bertentangan dengan Keputusan Menkes RI No. 829 tahun 1999 tentang persyaratan kesehatan perumahan dan lingkungan pemukiman, salah satu persyaratan adalah perumahan tidak terletak pada daerah bekas TPAS. Lokasi TPAS Terjun yang berada di sekitar perumahan penduduk sangat berpeluang menimbulkan berbagai permasalahan lingkungan, diantaranya pencemaran udara di luar maupun di dalam rumah. Timbunan sampah yang ada di TPAS Terjun menimbulkan bau yang tidak sedap. Tercemarnya udara di sekitar TPAS menyebabkan kesehatan lingkungan terganggu (Sukamawa et al, 2013).

Undang-undang No.23 tahun 1992 mengenai kesehatan menyatakan bahwa upaya kesehatan lingkungan diselenggarakan untuk mewujudkan kualitas lingkungan yang sehat dan dilaksanakan terhadap tempat umum, lingkungan pemukiman, tempat kerja, angkutan umum dan lingkungan lainnya yang meliputi penyehatan air, udara, pengamanan limbah padat, limbah cair, limbah gas, radiasi, kebisingan, pengendalian vektor dan penyehatan lainnya. TPAS mempunyai fungsi yang sangat penting, namun dapat menimbulkan dampak yaitu menurunnya kualitas 
lingkungan yang disebabkan karena tumpukan sampah yang mengandung berbagai polutan yang dapat menyebabkan pencemaran udara. Salah satu standart baku mutu yang ditetapkan oleh Keputusan Menteri Kesehatan RI No : 1077/MENKES/PER/V/2011 mengenai udara yang sehat adalah jumlah mikroorganisme $<700 \mathrm{CFU} / \mathrm{m}^{3}$ udara (Soemirat, 1994). Data dari Puskesmas Terjun Kecamatan Medan Marelan menyatakan bahwa penyakit ISPA selama bulan Januari 2011 sampai dengan Desember 2011 dengan jumlah kasus sebanyak 1.640 berada di urutan pertama dari sepuluh penyakit terbanyak di Puskesmas (Dinas Kesehatan Kota Medan, 2011).

Hampir semua kota mempunyai TPAS, tidak terkecuali Kota Medan. Metode pengelolaan sampah yang diterapkan oleh Dinas Kebersihan Kota Medan adalah Open Dumping yaitu sampah yang masuk ke TPAS dibuang atau dipaparkan langsung ke lokasi TPAS tanpa melalui proses tertentu. Cara ini tidak direkomendasikan lagi mengingat banyaknya potensi pencemaran lingkungan yang dapat ditimbulkan seperti perkembangan vector penyakit seperti lalat, tikus dan lain-lain. Polusi air akibat banyaknya lindi (cairan sampah) yang timbul. Estetika lingkungan yang buruk karena pemandangan yang kotor (Syafalni dan Satrio, 2007).

Pemerintah Kota Medan memiliki dua TPAS, diantaranya adalah TPAS Terjun. TPAS Terjun berjarak \pm $14 \mathrm{~km}$ dari pusat kota, dengan luas $137.563 \mathrm{~m}^{2}$ dan beroperasi sejak 7 Januari 1993. Berlokasi di Kelurahan Terjun Kecamatan Medan Marelan. Pengoperasian TPAS ini masih dilakukan dengan sistem open dumping (pembuangan terbuka) sehingga dapat menimbulkan dampak negatif terhadap kesehatan masyarakat di sekitarnya (Dinas Kebersihan Kota Medan, 2012).

\section{Metode}

\section{Jenis dan Desain Penelitian}

Penelitian ini bersifat Observasi yaitu Kegiatan Pengamatan untuk melihat seberapa banyak jumlah koloni yang tubuh pada media yang digunakan akibat dari perlakuan.

\section{Bahan dan Alat}

Bahan yang digunakan adalah udara di sekitar TPAS yang diambil di lokasi TPAS dan daerah pemukiman masyarakat, sisi kanan dan kiri TPAS. Media yang digunakan adalah Plate Count Agar (PCA). Alat yang di gunakan untuk pengambilan sampel adalah Mas Exampler dengan code Mas 100, petridish, inkubator, autoklaf dan biosafety.

\section{Mikroorganisme}

Sampel udara diambil di TPAS Terjun dan daerah pemukiman masyarakat di sekitar TPAS Terjun pada sisi kanan dan kiri dari TPAS dengan titik sampel yang tersebar pada jarak $0 \mathrm{~m}$ di lokasi TPAS dan keluar ke arah perumahan penduduk 100 m, 250 m, 500 m, 750 m dan $1000 \mathrm{~m}$.

Pengukuran sampel udara dilakukan dengan cara, alat pengambil sampel (Mas Exampler dengan code Mas 100) diletakkan di atas meja, kemudian alat tersebut dihidupkan, lalu tutup alat dibuka serta petridis yang berisi media PCA dimasukkan kedalam alat tersebut, kemudian ditutup serta diarahkan menghadap ke atas, diatur waktu selama 15-30 menit dengan daya sedot 100 liter/menit (Merck MAS-100, 2002) Setelah selesai media dibawa ke laboratorium, lalu diinkubasi pada $37^{\circ} \mathrm{C}$ selama 24 jam. Koloni yang tumbuh (bakteri dan jamur) dihitung pada media.

\section{Menghitung Mikroorganisme Udara}

Dilakukan penghitungan jumlah mikroorganisme yang tumbuh pada media PCA dari sampel udara yang diambil di TPAS Terjun dan daerah pemukiman masyarakat di sekitar TPAS Terjun pada sisi kanan dan kiri dari TPAS dengan titik sampel yang tersebar pada jarak 0 $m$ di lokasi TPAS dan keluar ke arah perumahan penduduk 100 m, 250 m, 500 m, 750 m dan 1000 m.

Setelah dilakukan Pengambilan sampel udara dari alat pengambil sampel (Mas Exampler dengan code Mas 100) yang diletakkan di atas meja, maka dilakukan pembiakan di laboratorium.

\section{Hasil}

\section{Jumlah Mikroorganisme Udara}

Penelitian dilakukan di TPAS dan di sekitar rumah penduduk di sekitar TPAS Terjun Kecamatan Medan Marelanuntuk mengetahuijumlahmikroorganisme udara (bakteri dan jamur). Hasil pemeriksaan laboratorium terhadap pengukuran jumlah mikroorganisme udara dapat dilihat pada Tabel 1.

Tabel 1. Jumlah Mikroorganisme Udara Berdasarkan Jarak

\begin{tabular}{cc} 
dari TPAS & $\begin{array}{c}\text { Jumlah } \\
\begin{array}{c}\text { Jarak dari TPAS } \\
\text { (meter) }\end{array}\end{array}$ \\
\hline 0 & $\begin{array}{c}\text { mikroorganisme } \\
\left(\mathrm{cfu} / \mathrm{m}^{3}\right)\end{array}$ \\
100 & 2874 \\
250 & 2294 \\
500 & 1913 \\
750 & 966 \\
1000 & 662 \\
& 517 \\
\hline
\end{tabular}

Dari hasil seperti pada Tabel 1 di atas dapat terlihat bahwa jumlah mikroorganisme udara yang terbanyak pada jarak $0 \mathrm{~m}$ (pusat TPAS) sebanyak 2874 $\mathrm{cfu} / \mathrm{m}^{3}$. Semakin jauh jarak dari titik pusat TPAS menunjukkan bahwa jumlah mikroorganisme semakin sedikit. Pada jarak 1000 m jumlah mikroorganisme dijumpai yang paling sedikit. Jumlah mikroorganisme pada lokasi titik pusat TPAS melebihi dari standart baku mutu yang telah ditetapkan. Populasi mikroorganisme udara yang tertinggi di titik pusat TPAS inilah menyebar ke daerah sekitarnya. Dari hasil ini menunjukkan bahwa jarak yang aman dari TPAS Terjun adalah pada jarak $\geq 750 \mathrm{~m}$ dari TPAS, karena pada jarak tersebut jumlah mikroorganisme $<700 \mathrm{cfu} / \mathrm{m}^{3}$.Semakin jauh dari titk pusat TPAS jumlah mikroorganisme semakin sedikit dimungkinkan karena mikroorganisme tidak bisa bertahan hidup pada kondisi yang tidak sesuai dengan 
keberadaannya misalnya karena terpaparnya dengan sinar matahari.

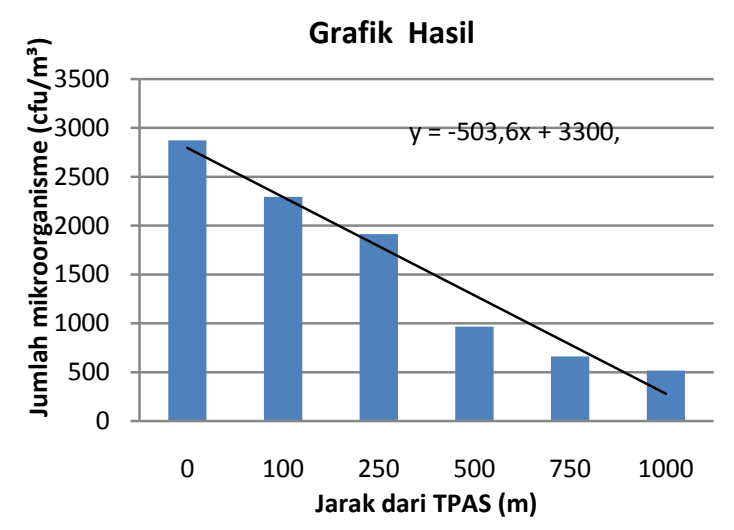

Gambar: Grafik Hubungan Jarak dari TPAS Terhadap JumlahMikroorganisme.

Gambar di atas dapat diketahui adanya hubungan yang linier ( $\mathrm{Y}=-503.66 \mathrm{X}=+3300.5)$ antara jarak dari TPAS dengan jumlah mikroorganisme. Korelasi antara jarak dari TPAS dengan jumlah mikroorganisme $\left(\mathrm{cfu} / \mathrm{m}^{3}\right)$ sebesar 0,957 . Hal ini menunjukkan hubungan yang erat antara jumlah mikroorganisme dengan jarak dari TPAS adalah sebesar 95,7\%. Sedangkan variasi yang terjadi terhadap banyaknya jumlah mikroorganisme sebesar 91,6\% disebabkan oleh jarak dari TPAS dan sisanya 8,4\% disebabkan oleh faktor lain.

Kemungkinan tingginya populasi mikroorganisme udara di daerah TPAS Terjun juga disebabkan oleh banyaknya sampah organik (74,07\%) yang terdapat di TPAS Terjun merupakan tempat berkembang biak mikroorganisme. Mikroorganisme ini hidup dengan memperoleh makanan berupa zat organik dari lingkungannya. .Bakteri yang mendapatkan zat organik dari sampah, kotoran, bangkai dan juga sisa makanan yang dibuang ke TPAS. Bakteri ini menguraikan zat organik dalam makanan menjadi zat anorganik, yaitu $\mathrm{CO}_{2}, \mathrm{H}_{2} \mathrm{O}$, energi dan mineral. Disamping itu mikroorganisme juga mengurai bahan-bahan organik dan limbah organik yang memberi manfaat kepada manusia. Penguraian dalam kondisi tanpa oksigen (anaerobik), material organik akan menjadi gas amoniak, hidrogen sulfida $\left(\mathrm{H}_{2} \mathrm{~S}\right)$, methana $\left(\mathrm{CH}_{4}\right)$ dan senyawa lain yang lebih sederhana. Bahrin et al (2011) menunjukkan bahwa sampah organik dapat menghasilkan biogas dan bermamfaat bagi manusia.

Topografi permukaan tanah asli TPAS Terjun relatif datar dengan ketinggian elevasi $\pm 2,5-3,0 \mathrm{~m}$ dari permukaan laut, hal ini sangat mendukung untuk hidup dan berkembangbiaknya mikroorganisme.Kelembaban udara untuk kota medan rata-rata berkisar antara 78-82\%. Kelembaban udara yang relatif rendah yaitu $<20 \%$ dapat menyebabkan kekeringan selaput lendir membran, sedangkan kelembaban tinggi akan meningkatkan pertumbuhan mikrorganisme. Udara terdiri dariberbagai lapisan hingga ketinggian sekitar 1000 km. Lapisan yang terdekat dengan bumi disebut troposfer. Jumlah dan macam mikroorganisme dalam suatu volume udara akan bervariasi sesuai dengan lokasi, kondisi cuaca dan jumlah orang yang ada. Hal yang senada juga diteliti oleh Prasasti et al (2005) mengenai pengaruh kualitas udara dalam ruangan ber AC terhadap gangguan kesehatan dengan hasil adanya gangguan kesehatan terhadap karyawan yang bekerja pada ruangan AC yang udara disekitarnya tercemar.

Banyaknya truk-truk sampah yang masuk ke lokasi TPAS menyebabkan banyaknya debu di sekitar perumahan penduduk. Daerah yang berdebu hampir selalu mempunyai populasi mikroorganisme atmosfer yang tinggi. Pengaruh angin juga menentukan keberadaan mikroorganisme di udara. Kecepatan angin Kota Medan rata-rata sebesar 0,42 $\mathrm{m} /$ detik. Pada udara yang tenang, partikel cenderung turun oleh gravitasi, tapi sedikit aliran udara dapat menjaga mikroorganisme dalam suspensi untuk waktu yang relatif lama. Angin penting dalam penyebaran mikroorganisme karena membawa mereka lebih jauh. Kecepatan angin juga memproduksi turbulensi udara yang menyebabkan distribusi vertikal mikroorganisme udara. Pola cuaca global juga mempengaruhi penyebaran vertikal. Ketinggian membatasi distribusi mikroorganisme di udara. Semakin tinggi dari permukaan bumi, udara semakin kering, radiasi ultraviolet semakin tinggi, dan suhu semakin rendah sampai bagian puncak troposfer. Hanya spora yang dapat bertahan dalam kondisi ini, dengan demikian, mikroorganisme yang masih mampu bertahan pada ketinggian adalah mikroorganisme dalam fase spora dan bentuk-bentuk resisten lainnya (Budiarti et al, 2007).

Wikansari et al (2012) mengatakan bahwa pencemaran udara yang disebabkan oleh mikroorganisme juga dapat menyebabkan penyakit nosokomial bagi pasien yang berada di rumah sakit. Mikroorganisme udara berasal dari 3 fenomena lingkungan yaitu partikel debu, droplet dan inti droplet. Droplet udara yang terbentuk selama aktifitas manusia bisa mengandung debu saja ataupun debu material biologi seperti bakteri. Droplet yang mengandung mikroorganisme udara akan masuk dan berdistribusi melalui aliran udara dan menyebabkan terjadinya resiko penularan infeksi. Mikroorganisme dengan jumlah yang banyak lebih memungkinkan untuk terjadinya infeksi (Budiarti et al, 2007).

Udara tidak mengandung mikroorganisme secara alami, tetapi kontaminasi dari lingkungan sekitarnya mengakibatkan udara mengandung berbagai mikroorganisme, misalnya dari debu, air, proses aerasi, dari penderita ISPA dan lain-lain. Mikroorganisme yang terdapat di udara biasanya melekat pada bahan padat misalnya debu atau terdapat dalam tetesan air (droplet). Jika dalam suatu ruangan banyak terdapat debu, mikroorganisme yang ditemukan di dalamnya juga bermacam-macam (Budiyono, 2001).

\section{Kesimpulan}

Berdasarkan hasil penelitian yang telah dilakukan,maka dapat ditarik suatu kesimpulan sebagai berikut :

1. Kualitas udara di sekitar lokasi TPAS Kelurahan Terjun Kecamatan Medan Marelan tidak memenuhi syarat kesehatan disebabkan oleh adanya 
mikroorganisme sudah di atas batas baku mutu (>700 $\mathrm{cfu} / \mathrm{m}^{3}$ )

2. Semakin banyak jumlah mikroorganisme di udara maka semakin besar kemungkinan akan terjadi infeksi penyakit disekitar TPAS.

3. Jarak yang aman bagi masyarakat adalah $\geq 750 \mathrm{~m}$ dari TPAS.

\section{Saran}

Berdasarkan kesimpulan dan pembahasan di atas, maka didapat saran- saran:

1. Bagi masyarakat yang bertempat tinggal di daerah $\leq 750 \mathrm{~m}$ dari TPAS disarankan pindah dari lokasi sekitar TPAS.

2. Bagi petugas kebersihan dan pemulung agar menjalankan prosedur keselamatan kerja dengan ketentuan dan peraturan yang berlaku serta menjalankannya dalam melaksanakan tugas.

3. Sebagai masukan bagi pemerintah kota Khususnya Dinas Kebersihan dan Pertamanan, untuk memperbaiki sistim pengelolaan sampah yang ada dengan metode dan teknik pengolahan sampah yang berwawasan lingkungan sehingga tidak menimbulkan dampak negatif terhadap masyarakat dan lingkungan.

4. Sebagai masukan bagi pemerintah kota Khususnya Dinas Sosial dan Dinas Kesehatan untuk memperhatikan tempat tinggal bagi masyarakat yang layak huni

5. Hasil penelitian dapat menambah wawasan ilmu pengetahuan dan sebagai informasi mengenai kualitas udara yang berada di sekitar Tempat Pembuangan Akhir Sampah, khususnya TPAS Terjun Kecamatan Medan Marelan, serta sebagai dokumen ilmiah yang dapat dikembangkan oleh peneliti selanjutnya, khususnya berbagai dampak yang diakibatkan oleh TPAS.

\section{Daftar Pustaka}

Budiarti, Y.L., Noormuthmainah dan Rahmiati. 2007. Jenis Bakteri dan Jamur Kontaminan Udara di Ruang Perawatan Sub Bagian Penyakit Dalam Rumah Sakit Umum Daerah Banjarbaru. Jurnal Kedokteran. 15(1): 41-48.

Budiyono, A. 2001. Pencemaran Udara Dampak Pencemaran Udara Pada Lingkungan. Berita Dirgantara. 2(1): 21-27.

Candara, B. 2006. Pengantar kesehatan lingkungan, Jakarta, EGC.

Darmasetiawan, M. 2012. Perencanaan Tempat Pembuangan Ahir (TPA) Ekamitra Enginering, Jakarta.

Dinas Kebersihan Kota Medan. 2015. Laporan Final Studi Kelayakan Lokasi Tempat Pembuangan Ahir Sampah (TPA), Pemerintah Kota Medan.
2012. Penyusunan DED Revitalisasi TPA Terjun dan Namo Bintang. Pemerintah Kota Medan.

Fitria, L., Wulandari,. R. A., Hermawati, E dan Susanna, D. 2008. Kualitas Udara Dalam Ruang Perpustakaan Universitas " $\mathrm{X}$ ” Ditinjau dari Kualitas Biologi, Fisika dan Kimia. Makara Kesehatan. 12(2): 76-82.

Keputusan Menteri Kesehatan RI No. 829 Tahun 1999. Tentang Persyaratan Kesehatan Perumahan dan Lingkungan Pemukiman. No:

1077/MENKES/PER/V/2011. Mengenai Udara Yang Sehat.

Nandi. 2005. Kajian Keberadaan Tempat Pembuangan Akhir (TPA) Leuwigajah Dalam Konteks TataRuang. Jurnal GEA Jurusan Pendidikan Geografi. 5(9):1-7

Paramitha, I dan Sudarmaji. 2008. Hubungan Jarak Terhadap Kualitas kimia Air Tambak dan keluhan Kesehatan Masyarakat Konsumen Ikan Hasil Tambak di Sekitar Tempat Pembuangan Akhir Sampah Benowo. Jurnal Kesehatan Lingkungan. 4(2): 30-48.

Pemerintah Kota Medan. 2011. Laporan Kependudukan Desa Terjun, Pemerintah Kota Medan.

Prasasti, C.I., Mukono, J dan Sudarmaji. 2005. Pengaruh Kualitas Udara Dalam Ruangan Ber-AC Terhadap Gangguan Kesehatan. Jurnal Kesehatan Lingkungan. 1(2): 160-169.

Santoso, I.N. 2010. Bakteriologi Klinik, Pusat Pendidikan Tenaga Kesehatan Departemen Kesehatan RI, Jakarta.

Soedojo, P. 2011. Dampak Pada Kwalitas Udara. Kantor Menteri Negara Kependudukan dan Lingkungan Hidup dan UGM, PPLH Yokyakarta.

Soemirat, J. 2009. Kesehatan Lingkungan, Gadjah Mada University Press, Yogyakarta.

Standart Nasional Indonesia Nomor 03-3241-1994, Mengenai Tempat Pembuangan Akhir Sampah. Suharsimi, A. 2005. Manajemen Penelitian, Rineka Cipta, Jakarta.

Sulistyorini, L. 2005. Pengelolaan Sampah Dengan Cara Menjadikan Kompos, Jurnal kesehatan Lingkungan. 2(1): 77-84.

Syafalni dan Satrio. 2007. Studi Air Tanah di Sekitar Tempat Pembuangan Ahir Sampah Bantar Gebang Bekasi Jawa Barat, Jurnal Purifikasi. 8(2): 109-114.

Tamod, E.Z. 2008. Karakteristik Mutu Udara di Pusat dan Sekitar TPA Sumompo, Jurnal Formas. 2(1): 94-97. 